\title{
Registro através de Armadilhamento Fotográfico para Puma concolor (Linnaeus, 1771), no município de Pouso Alegre MG
}

\author{
Alyson José Gonçalves dos Santos ${ }^{a}$, Ana Barbara Barros ${ }^{b}$, Alexandre Martins Costa Lopes ${ }^{c}$. \\ a Laboratório de Botânica, Ecologia e Zoologia, Universidade do Vale do Sapucaí, Pouso Alegre, MG, Brasil. \\ b Laboratório de Botânica, Ecologia e Zoologia, Universidade do Vale do Sapucaí, Pouso Alegre, MG, Brasil. \\ c Instituto de Pesquisa e Conservação de Tamanduás no Brasil; PPGBC - Programa de Pós-Graduação em Biodiver- \\ sidade e Conservação, Universidade Federal do Piauí (UFPI), Parnaíba, Piauí, Brasil.
}

\section{RESUMO}

Várias espécies têm a capacidade de tolerar a influência do homem, convivendo com essas ações próximas a florestas e áreas rurais. A Onça-parda (Puma concolor) é um mamífero presente na Mata Atlântica, classificado como vulnerável (VU). No Brasil, a espécie ocorre em todo seu território, possuindo ampla distribuição em todos os biomas brasileiros, podendo ocupar plantações de cana-de-açúcar e habitats relacionados à redução da cobertura vegetal; além disso, áreas de florestamento com moderada perturbação também são susceptíveis para esta espécie. Esse estudo tem o intuito de descrever áreas de ocorrência da espécie, através de registros fotográficos e rastros deixados por este felino, no Sul de Minas Gerais. Na área em estudo foram implantados transectos de amostragem lineares e paralelos, com uma distância de $200 \mathrm{~m}$. Ao longo de cada transecto foram determinados pontos de amostragem georreferenciados definidos como pontos estratégicos para captura fotográfica dos animais. Foram colocadas 6 armadilhas fotográficas alternadas dentro de cada transecto que eram checadas a cada 30 dias. $\mathrm{O}$ primeiro indício da presença da espécie na unidade de conservação (UC) Parque Natural Municipal Professor Afonso Bonillo Fernandes foi a localização de fezes no interior do fragmento. A amostra fecal foi medida e fotografada. $O$ registro fotográfico da espécie Puma concolor ocorreu em um dos pontos localizados dentro da zona de amortecimento da UC, indicando a possibilidade de uso desse recurso como um corredor ecológico, gerando um alerta para possíveis conflitos etnozoológicos, sendo necessária a criação de medidas mitigatórias para tais conflitos.

Palavras-chave: Armadilha Fotográfica, Mata Atlântica, Onça-parda.

\section{ABSTRACT:}

Several species have the ability to tolerate the influence of man, coexisting with these actions close to forests and rural areas The puma (Puma concolor) is a mammal present in the Atlantic Forest, classified as vulnerable (VU). In Brazil, the species occurs throughout its territory, having a wide distribution in all Brazilian biomes, being able to occupy sugarcane plantations and habitats related to the reduction of vegetation cover; in addition, areas of afforestation with moderate disturbance are also susceptible to this species. This study aims to describe areas of occurrence of the species, through photographic records and tracks left by this feline, in the south of Minas Gerais.Linear and parallel sampling transects were implemented in the area, with a distance of $200 \mathrm{~m}$. Along each transect, georeferenced sampling points were determined, defined as strategic points for photographic capture of the animals. Six alternate camera traps were placed inside each transect and che-cked every 30 days. The first indication of the species' presence in the Professor Afonso Bonillo Fernandes Municipal Natural Park was the location of feces inside the fragment. The fecal sample was measured and photographed. The photographic record of the Puma concolor species occurred at one of the points located within the buffer zone of the UC, indicating the possibility of using this resource as an ecological corridor, generating an alert for possible ethnozoo-logical conflicts, requiring the creation of mitigation measures for such conflicts.

Keywords: Atlantic Forest; Photo Trap; Puma.

*Autor correspondente: Alyson José Gonçalves dos Santos, Bacharel em Ciências Biológicas, Sitio São Vicente, Heliodora, Minas Gerais. (35)99860-6551; alysonmastzoo@gmail.com 


\section{INTRODUÇÃO}

A degradação da vegetação da Mata Atlântica e a defaunação tem como principal causa atividades antrópicas, devido as alterações no solo, pelo manejo intensivo e a fragmentação dos habitats naturais, podendo causar um efeito de cascata em diferentes índices, levando a extinção local das espécies (GRAIPEL, 2016).

Várias espécies tem a capacidade de tolerar a influência do homem, convivendo com essas ações próximas a florestas e áreas rurais (KORONTAI, 2008). Espécies endêmicas e também as que necessitam de uma grande disponibilidade de área, apresentam uma rápida resposta ao movimento de fragmentação, além disso, hoje, há uma grande variedade taxonômica que precisa ser protegida, devido ao grande índice de ameaça a extinção (PINTO et al., 2006).

Em especial, a classe Mammalia, ordem Carnívora aparecem dentre os animais mais sujeitos a extinção local em áreas fragmentadas. Por necessitarem de uma ampla área de distribuição geográfica apresentam pouca densidade e de modo direto são acometidos a atividades antrópicas (NAKANO, 2006). A Onça-parda (Puma concolor) é um mamífero selvagem distribuído no Hemisfério Ocidental, (GHELER-COSTA et al., 2018). Atualmente é dividido em seis grupos geográficos sistemáticos. São eles: $P$. Concolor Cougar, para América do Norte, $P$. concolor costaricensis na América Central, $P$. concolor capricornensis no Sudeste da América do Sul, $P$. concolor concolor pelo Norte da América do Sul, $P$. concolor cabrerae dentre a América do Sul Central, e $P$. concolor puma na América do Sul (DE AZEVEDO et al., 2013).

No Brasil, a espécie ocorre em todo seu território, possuindo ampla distribuição em todos os biomas brasileiros, podendo ocupar plantações de cana-de-açúcar e habitats relacionados à redução da cobertura vegetal; além disso, áreas de florestamento com moderada perturbação também são susceptíveis para esta espécie (PENTEADO et al., 2019). Está espé- cie é classificada como vulnerável (VU) para a Mata Atlântica de acordo com a sua avaliação de risco de extinção no bioma (DE AZEVEDO et al., 2013).

Percebe-se que grandes felinos necessitam abranger grandes áreas de vida, tornando-se extremamente vulneráveis à redução e fragmentação de áreas florestais. Quando uma população está isolada geograficamente, esta, fica exposta à uniformidade genética, onde ocorre a redução da sua habilidade de se adaptar às mudanças ambientais e diversos fatores que se aliam para desencadear a extinção da espécie (AZEVEDO et al., 2021).

A onça parda é o maior carnívoro ocorrente na região sul de Minas Gerais (AZEVEDO et al., 2021), e, apesar da reconhecida importância dessa espécie para o ecossistema, não há atuais estudos na área sobre o seu comportamento de uso territorial, dado este extremamente importante para subsídio de ações de manejo conservacionista. Dessa forma, considerando a importância dessa espécie para a biodiversidade e levando em consideração a conservação e perpetuidade esse estudo tem o intuito de descrever áreas de ocorrência da espécie, através de registros fotográficos e rastros deixados por este felino, no Sul de Minas Gerais.

\section{MATERIAL E MÉTODOS}

O estudo se dá na unidade de conservação de proteção integral (UCPI) com cerca de 2014 hectares (ha), denominados Parque Natural Municipal Professor Fernando Afondo Bonillo, predominantemente, no Bioma Mata Atlântica, sudeste do Brasil na cidade de Pouso Alegre sul de Minas Gerais, em que dominam as fitofisionomias de Floresta Estacional Semidecidual Montana (figura 1). Os remanentes de floresta atlântica nas áreas referidas, localizam-se em fragmentações isoladas na paisagem, sendo, topos de serras, planaltos e matas que margeiam curso d'agua, os tipos de solos predominantemente são metas-siltito, meta-arenitos e meta-conglomerados (BORGES et al., 2012). 
A topografia desse município é caracterizada pelo relevo plano- $30 \%$; ondulado- $60 \%$; montanhoso- $10 \%$, aproximadamente. Nas coordenadas geográficas $22^{\circ} 13^{\prime} 00$ 'S e $045^{\circ}$ 58' 00" W localiza-se na Serra de Santo Antônio, conforme as altitudes baseiam-se em $875 \mathrm{~m}$ e $1180 \mathrm{~m}$. O clima é mesotérmico, com 2 a 3 meses secos/ano, apresentando verões chuvosos brandos e invernos secos. O nível pluviométrico encontra-se entre 1300 e 1700mm (DJALLES COSTA et al., 2012).

$\mathrm{Na}$ área foram implantados transectos de amostragem lineares e paralelos, com uma distância de $200 \mathrm{~m}$. Ao longo de cada transecto foram determinados pontos de amostragem georreferenciados definidos como pontos estratégicos para captura fotográfica dos animais. Foram colocadas 6 armadilhas fotográficas alternadas dentro de cada transecto que eram checadas a cada 30 dias. A área preservada mante-se livre de impactos rigorosos atuais, sendo composta por uma vegetação em diferentes estágios de sucessão. A matriz de entorno do fragmento no qual o parque está inserido é composta por áreas de pastagens antrópicas consideradas como zona rural e por pastagens entremeadas por loteamentos habitacionais em zonas de expansão urbana do município de Pouso Alegre-MG.

As câmeras foram instaladas em novembro de 2019 e desativadas em maio de 2021, em 6 pontos pré-determinados para o monitoramento das espécies de mamíferos da UCPI. Foi totalizado 18 meses de amostragem, num total de 540 dias de armadilhas em campo, e as buscas ativas que eram realizadas na segunda quinzena de cada mês de amostragem, totalizaram um total de 18 dias com cerca de 6 horas de buscas, totalizando 108 horas de buscas ativas.

Através deste relata-se o primeiro registro através de Armadilhamento Fotográfico de Puma concolor no município de Pouso Alegre, sul de Minas Gerais, e é apresentada uma síntese sobre a distribuição conhecida para este Felino, na região sul do estado de Minas Gerais. O registro foi obtido através de armadilhamento fotográfico em 20 de outubro de 2020. O mapa de distribuição da espécie, foi criado através do software QGIS (Figura 1).

Figura 1: Mapa de localização com os registros de Puma concolor no sul de Minas Gerais.

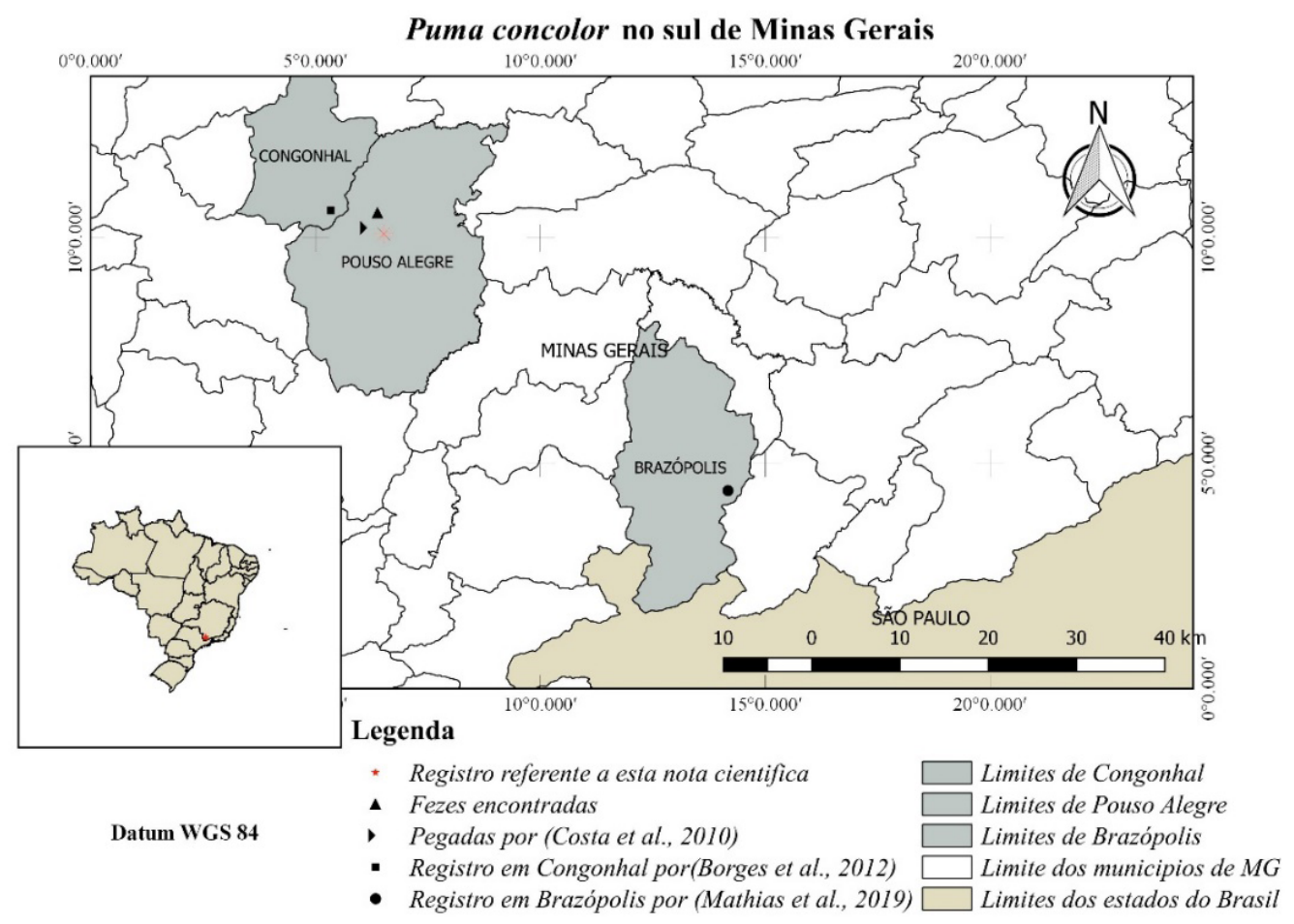

Fonte: Do autor (Software QGIS) 


\section{RESULTADOS E DISCUSSÃO}

Os primeiros indícios da presença da espécie na UC foi a localização de fezes encontrada durante a busca ativa por vestígios em uma trilha no interior do fragmento. A amostra foi medida e fotografada, e, ainda assim, através da visualização do conteúdo defecado, pode-se supor através dos pelos presentes nas fezes, que o indivíduo estivesse se alimentado de Sus scrofa (Javali), espécie considerada invasora no brasil (figura 2a). Em outra trilha localizada na zona de amortecimento da UC, a espécie Puma concolor foi registrada por Armadilha Fotográfica do tipo Bushnell (coordenadas geográficas: $\left.22^{\circ} 13^{\prime} 02^{\prime \prime} S 45^{\circ} 57^{\prime} 37^{\prime \prime} \mathrm{O}\right)$, local esse, adjacente a uma área queimada, ocorrida um mês anterior ao registro. Na imagem foi possível constatar que se tratava de um individuo adulto com musculatura e pelagem saudáveis (figura $2 b$ ). A espécie já foi registrada anteriormente em outros municípios do sul de Minas Gerais, através de armadilhamento fotográfico e vestígios.

Figura 2: Registros da presença de Puma concolor na UCPI em Pouso Alegre

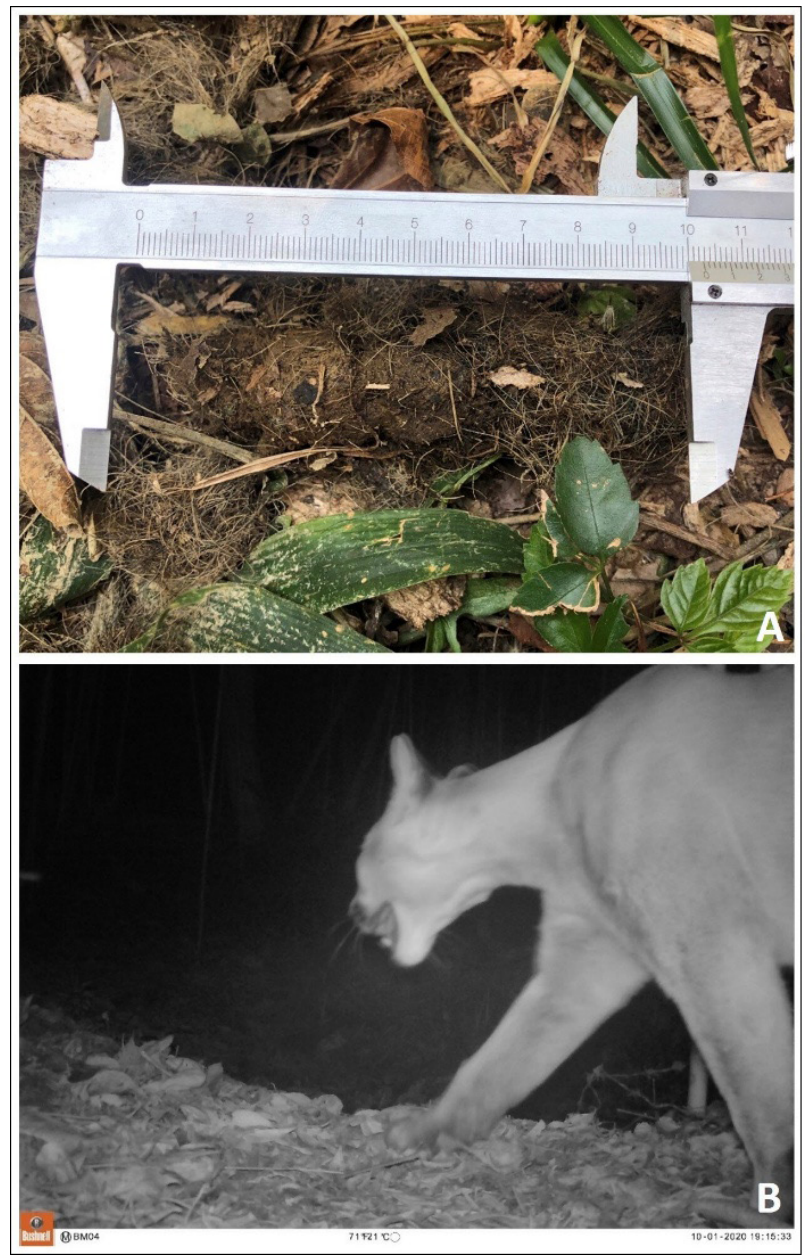

Fonte: Do autor, 2021.

No Brasil a espécie está amplamente distribuída em todos os biomas, entretanto mesmo estando bem distribuída em todo território nacional, as suas populações vem sendo cada vez mais delimitadas, ou até mesmo extintas em algumas localidades, como exemplo os campos sulinos nos pampas que os registros vem sendo cada vez mais escassos. Apesar de ser um individuo com ampla distribuição, há lo- cais que atualmente são escassos os registros destes animais, como por exemplo as onças-pardas norte americanas já são cada vez mais escassas, em relação as populações da américa central e do sul (DE AZEVEDO et al., 2013).

Felinos silvestres estão entre as espécies mais ameaçadas do mundo, sendo afetadas diretamente por fatores locais, seja pela descaracterização de habitats, condições alimenta- 
res, forte pressão de caça em função do grande prejuízo que causam ao predarem criações domésticas, além de sempre se apresentarem em baixa densidade natural (LAZO, 2004).

Espécies de grandes carnívoros, como a onça-pintada e o puma são indicadoras da saúde dos ecossistemas, a presença destes indivíduos apresenta a necessidade de se manter o equilíbrio ecológico dentro de um fragmento de mata atlântica, pois uma vez que são caracterizadas como espécies guarda-chuvas, são extremamente necessários para manter as espécies pioneiras e dispersoras no ecossistema, sendo também controladoras de populações, 0 que dá uma grande relevância para o estudo do ecossistema de um fragmento (BRANDÃO, 2004)

Estes animais são chamados keystone species que são "pedras fundamentais" ou "chaves" para a qualidade ambiental. Seu desaparecimento provoca o fenômeno conhecido como "efeito cascata", ou seja, severas disfunções dos níveis tróficos, com consequências interligadas do topo até a base da pirâmide alimentar, incluindo impactos severos na vegetação até extinções locais, regionais e globais (JORDAN, 2009).

No Brasil, ainda são escassos os estudos de mapeamento geográfico e densidade populacional da espécie, devido a grande dificuldade de se estudar a espécies em técnicas não invasivas, consequentemente, estudos que abordem o seu direcionamento devem ser salientados para que se possa traçar políticas de fomento em relação a espécie (DE AZEVEDO et al., 2013).

Em tamanho, é o segundo maior felino das américas, perdendo em tamanho somente para a onça-pintada (Panthera onca). A onça parda é um animal de hábitos generalistas, consumindo uma grande variedade de presas, que irá depender da variabilidade disponível no ambiente. O peso médio de um macho adulto pode variar entre 40 e $72 \mathrm{~kg}$, enquanto nas fêmeas varia de 34 a $48 \mathrm{~kg}$, no brasil e espécie geralmente se alimente de animais mais pequenos, como tatus, veados e pacas, já há indícios de espécimes norte-americanos predando a grande fauna como alces (LUPINO et al., 2021).

Entre os anos de 2004 e 2005 Puma concolor, foi registrada através de pegadas ao longo da trilha principal da UCPI em Pouso Alegre, (COSTA et al., 2010). Já no ano de 2011, Borges et al., 2012, registrou através de armadilha fotográfica, um individuo em uma área queimada no município de Congonhal, cerca de $20 \mathrm{~km}$ do município de Pouso Alegre, concretizando que a espécie Puma-concolor na região, costuma utilizar locais devidamente fragmentados.

Mais recentemente, entre os anos de 2017 e 2018 no município de Brasópolis-MG, em uma parte da área Serra da Mantiqueira, na região Sul do estado de Minas Gerais, com cerca de $80 \mathrm{~km}$ da área de estudo em Pouso Alegre, foi registrado por armadilhamento fotográfico a espécie de Onça-parda (Puma-concolor), em uma remanescente de floresta próximo ao observatório Pico dos dias, um local com utilização antrópica turística (MATHIAS et al., 2019).

O estudo com carnívoros como a onça-parda, considerada uma espécie guarda-chuva, gera resultados que podem ser transformados em medidas de conservação da espécie, que implicam em preservação de habitats, dos processos ecossistêmicos e, indiretamente, de outras espécies (GHELER-COSTAet al., 2018), decorrente a isso o registro da espécie para a UCPI, se faz tão importante, pois estabelece estratégias de conservação para o fragmento, uma vez que espécies guarda-chuva tem o papel de manter equilíbrio ecológico do ecossistema (ALVES et al., 2013).

\section{CONCLUSÃO}

A ocorrência de onça-parda (Puma-concolor), não é um registro inovador para o bioma Mata Atlântica, sendo este um de seus locais de distribuição. $O$ último registro realizado para a espécie foi de vestígios dentro do parque realizado por Costa et al., (2010) demonstrando que 10 anos após a pesquisa a efetiva confirmação fotográfica do animal foi concretizada. 
Por outro lado, a ocorrência de tal individuo na zona de amortecimento, próxima a zona urbana, bem como a utilização deste local por outras espécies, nos concede a possibilidade desta fauna utilizar este recurso como um corredor ecológico, o que nos posiciona a uma questão para levantar medidas que evitem possíveis conflitos etnozoologicos.

Esses indícios demonstram a importância de se estudar a espécie no aspecto ecológico da cadeia alimentar, uma vez que o Javali (Sus scrofa), é uma espécie invasora, tendo como a onça parda seu possível predador, temos uma relevância muito grande dentro de uma ecologia trófica, uma vez que a espécie pode se adaptar a caça desta espécie invasora, e, servir como controlador populacional desta espécie.

\section{CONFLITO DE INTERESSE}

Não há conflito de interesse na pesquisa.

\section{REFERÊNCIAS}

ALVES, Iris Rianne Santana; DO NASCIMENTO, Gilson Miranda; MAROTI, Paulo Sérgio. Percepção Ambiental de Visitantes da RPPN Serra das Almas, Crateús/CE: A EscoIha da Espécie Guarda-Chuva Como Potencial Educativo e de Gestão. Revista Ambivalências, v. 1, n. 1, p. 90-102, 2013.

AZEVEDO, FC et al. A importância das florestas para um predador de ápice: ecologia espacial e seleção de habitat por pumas em um agroecossistema. Conservação Animal, v. 24, n. 3, pág. 499-509, 2021.

BORGES, A.F.S; DA SILVA, R. Comparação da riqueza faunística através de armadilhamento fotográfico em sítios preservados e impactados por incêndio em Floresta Estacional Semidecidual no sul de Minas Gerais. 2012. 36f. Monografia para TCC (Graduação em Ciências Biológicas) - Departamento de Ciências Biológicas da Universidade do Vale do Sapucaí, Pouso Alegre, 2012.
BRANDÃO, Thais Vargas. Identificação de novas unidades de conservação através de uma abordagem da ecologia de paisagem utlizando o conceito de múltiplas espécies guarda-chuva. Salão de Iniciação Científica (16.: 2004: Porto Alegre). Livro de resumos. Porto Alegre: UFRGS, 2004., 2004.

COSTA, Maurício Djalles et al. Densidade, tamanho populacional e conservação de primatas em fragmento de Mata Atlântica no sul do Estado de Minas Gerais, Brasil. Iheringia. Série Zoologia, v. 102, p. 5-10, 2012.

COSTA, Maurício Djalles; FERNANDES, Fernando Afonso Bonillo; DA SILVA VIANA, Douglas Henrique. Mamíferos não-voadores no Parque Municipal de Pouso Alegre, MG. Revista Brasileira de Zoociências, v. 12, n. 3, 2010.

DE AZEVEDO, Fernanda Cavalcanti et al. Avaliação do risco de extinção da Onça-parda Puma concolor (Linnaeus, 1771) no Brasil. Biodiversidade Brasileira-BioBrasil, n. 1, p. 107-121, 2013.

GHELER-COSTA, Carla et al. Ecologia trófica de onça-parda (Puma concolor) em paisagem agrícola. Revista em Agronegócio e Meio Ambiente, v. 11, n. 1, p. 203-225, 2018.

GRAIPEL, M. E. et al. Características associadas ao risco de extinção nos mamíferos terrestres da Mata Atlântica. Oecologia Australis, Florianópolis. v. 20, n. 1, p. 81-108. Jan. 2016.

JORDAN, Ferenc. Espécies-chave e teias alimentares. Transações filosóficas da Royal Society B: Biological Sciences , v. 364, n. 1524, pág. 1733-1741, 2009.

KORONTAI, V. N. Uso de espaço por carnívoros em uma área de Mata Atlântica insular (MAMMALIA: CARNIVORA). 2008. 32f. Monografia para graduação (Bacharel em 
Ciências Biológicas) - Departamento de Zoologia, Setor de Ciências Biológicas, da Universidade Federal do Paraná, Curitiba, 2008.

LAZO, Lizie Jatkoske. A mastofauna da Fazenda Figueira em uma área do Baixo Tibagi, Município de Londrina, Paraná. 2004. Tese de Doutorado. Universidade de São Paulo.

LUPINO, Lívia Martins et al. COMPREENSÃO DO CONCEITO DE CADEIA ALIMENTAR A PARTIR DE UMA PROBLEMÁTICA ATUAL DO ALTO RIO BATALHA:: ATAQUES DE ONÇA-PARDA. MIMESIS, v. 42, n. 1, p. 157-170, 2021.

MATHIAS, Nathan Filipe; DE VASCONCELOS CAMARGO, Flávio. Felinos de um remanescente florestal localizado na Serra da Mantiqueira, Sul de Minas Gerais. Revista Científica da FEPI-Revista Científic@ Universitas, v. 6, n. 1, 2019.

NAKANO, O. E. Ecologia e conservação de mamíferos carnívoros de Mata Atlântica na região do complexo estuarino lagunar de Cananeia, Estado de São Paulo. 2006. $217 \mathrm{f}$. Tese de Doutorado (Doutor em ecologia) - Instituto de Biologia da Universidade Estadual de Campinas, Campinas, 2006.

PAULA, T. A. R. et al. Aspectos do uso territorial por onça parda (Puma concolor), através de monitoramento via satélite, na região do Parque Estadual da Serra do Brigadeiro, MG. Arquivo Brasileiro de Medicina Veterinária e Zootecnia, v. 67, n. 1, p. 80-88, 2015.

PENTEADO, Homero Marconi et al. A onça no condomínio: o papel dos corredores ecológicos urbanos. Revista de Morfologia Urbana, v. 7, n. 2, p. e00109-e00109, 2019.

PINTO, L.P., et al. Mata Atlântica Brasileira: os desafios para conservação da biodiversidade de um hotspot mundial. Revista Biologia da conservação: essências, São Carlos:
RiMa, v. 1, p. 91-118, jan. 2006.

UBIALI, Daniel G. et al. É possível integrar pecuária à conservação da biodiversidade? Estudo de casos de depredação de ovinos por onça-parda (Puma concolor). Pesquisa Veterinária Brasileira, v. 38, n. 12, p. 2266-2277, 2018. 